\title{
Genetic Variation Among Fusarium oxysporum Isolates from Sugar Beet as Determined by Vegetative Compatibility
}

\author{
R. M. Harveson, Department of Plant Pathology, University of Florida, P.O. Box 110680, Gainesville 32611; and \\ C. M. Rush, Department of Plant Pathology, The Texas A\&M University System, Texas Agricultural Experiment \\ Station, P.O. Drawer 10, Bushland 79012
}

\begin{abstract}
Harveson, R. M., and Rush, C. M. 1997. Genetic variation among Fusarium oxysporum isolates from sugar beet as determined by vegetative compatibility. Plant Dis. 81:85-88.

One hundred sixty Fusarium oxysporum isolates were collected over a 3-year period (1992 to 1994) from diseased sugar beet and pigweed plants from seven counties in Texas. Disease symptoms on sugar beet included root-tip-rot symptoms with wilting and vascular necrosis, and wilting and vascular necrosis only. Pathogenicity testing on sugar beets indicated that 132 isolates of the 160 recovered were pathogenic and were considered to be $F$. oxysporum f. sp. betae (FOB). Of the 132 isolates of FOB, 28 were initially chosen as testers and paired in all possible combinations to estimate the number of vegetative compatibility groups (VCGs) present. Once VCGs were determined from the 28 isolates, a nitrate nonutilizing mutant (nit) 1 or nit 3 from each of the remaining isolates was paired against a Nit $\mathrm{M}$ from each of the established VCGs. Thirty-three isolates obtained from other sugar-beet-growing states also were tested for vegetative compatibility. A total of 95 of the 132 isolates of FOB from Texas were assigned to one of seven VCGs identified. Sixty-three isolates were assigned to VCG 1, with VCGs 2 through 7 containing $6,16,2,2,2$, and 4 isolates, respectively. VCGs 1,3 , and 6 were recovered from both sugar beet and pigweed. Two additional isolates collected from Texas in 1987 also belonged to VCG 1. A number of the isolates collected from Texas could not be assigned to any of the seven established VCGs. These included two single-member Nit Ms, 11 self-incompatible isolates, and 24 of unknown affiliation. None of the isolates from any one state were compatible with those from any other state. Results suggest that substantial variation exists among sugar beet isolates of FOB from the U.S., and that these populations of $F$. oxysporum are apparently distinct and endemic to their respective areas.
\end{abstract}

Texas sugar beet (Beta vulgaris L.) production suffers significant losses annually from a number of diseases caused by soilborne pathogens. These diseases often are found occurring in the same fields (15). The three major fungal diseases involved in this complex are Rhizoctonia root and crown rot, caused by Rhizoctonia solani Kühn, Aphanomyces root rot, caused by Aphanomyces cochlioides Drechs., and Fusarium root rot, caused by Fusarium oxysporum Schlechtend.:Fr. f. sp. betae (Stewart) W. C. Snyder \& H. N. Hans. (FOB) (15). Fusarium root rot is the least well characterized and understood of these diseases in Texas.

In 1931, Stewart first described a disease of sugar beet from Colorado that he called Fusarium yellows (32). The causal agent was identified as $F$. conglutinans var. betae Stewart and was later renamed $F$. oxysporum f. sp. betae (31). It was characterized by interveinal chlorosis, wilting,

Corresponding author: C. M. Rush

E-mail:cm-rush@tamu.edu

Accepted for publication 11 October 1996.

Publication no. D-1996-1121-04R

(C) 1997 The American Phytopathological Society and vascular necrosis. FOB has now been identified as a pathogen of sugar beet in eight states (31).

In 1971, a severe stalk blight of sugar beets grown for seed was observed in the Willamette Valley in Oregon (14). This pathogen was also identified as FOB and resembled isolates from Colorado in pathogenicity and cultural characteristics. Ten years later, another disease resembling Fusarium yellows was observed in Texas sugar beet fields (26) and has been increasing in severity since this initial report. Symptomatically, the disease in Texas is similar to Fusarium yellows in that affected plants may show no symptoms other than leaf yellowing, wilting, or vascular discoloration. However, it is often additionally characterized by a black tip rot that disintegrates root cortical tissue, leaving only vascular tissue intact. This tip rot can easily be confused with symptoms caused by $A$. cochlioides; however, the necrosis of vascular tissue is diagnostic for FOB (15; R. M. Harveson and C. M. Rush, unpublished).

The pathogen in Texas also was identified as $F$. oxysporum, although it was considered to be different from the Fusarium yellows pathogen due to a minimal production of macroconidia (26; R. M. Harveson and C. M. Rush, unpublished). Martyn et al. also showed, by isozyme analysis, that two Texas isolates were distinct from Fusarium yellows isolates from beet from Oregon and California, both morphologically and genetically (26).

Puhalla initiated the idea of grouping isolates of $F$. oxysporum into vegetative compatibility groups (VCGs) based on the use of nitrate nonutilizing (nit) mutants generated on media containing potassium chlorate (30). Correll et al. improved this technique by demonstrating that nit mutants of $F$. oxysporum could be subdivided into three phenotypically distinct classes based on the ability to utilize different nitrogen sources (6). Vegetative compatibility only occurs between complementary nit mutants sharing a common allele at each of several vegetatively incompatible loci. Thus, vegetatively compatible isolates demonstrate a high degree of relatedness and belong to the same VCG.

Historically, F. oxysporum isolates have been subdivided into formae speciales on the basis of virulence on a particular host, and further subdivided into races based on virulence to cultivars that vary in disease resistance. Vegetative compatibility can serve as a natural means to further subdivide closely related fungal populations ( 5 , 22,23), and also can estimate genetic diversity within and among these same populations $(4,9,18,20,29)$. Puhalla's nit mutant system was designed to test an evolutionary model for origin of formae speciales, races, and VCGs (30). The examination of numerous formae speciales has shown that the relationship among these parameters can vary from relatively simple $(4,7,20,21)$ to very complex $(8,9,18,28,29)$.

Because of the poorly understood nature of the genetic diversity of sugar beet isolates causing Fusarium root rot in Texas, this study was undertaken to examine a large collection of FOB isolates for vegetative compatibility. The second objective was to determine whether FOB isolates recovered from different hosts or from sugar beet with different symptoms were associated with specific VCGs. In addition, isolates from several other sugar-beet-growing states also were examined for vegetative compatibility. Preliminary reports have been published $(16,17)$.

\section{MATERIALS AND METHODS}

Collection and storage. From November 1992 through the 1994 growing season, 
160 Fusarium isolates were collected from symptomatic sugar beet and red root pigweed (Amaranthus retroflexus L.) plants from seven counties in Texas. Pigweed is a weed species closely related to sugar beet and commonly found in the Texas Panhandle. These counties represent the majority of the production areas of the state. Isolates were initially separated into two groups, those causing a tip rot, along with wilting and vascular necrosis, and those causing only vascular discoloration (non-tip-rot). They also were separated by host.

Affected roots were washed free of adhering soil. Root tissue pieces taken from the necrotic vascular elements in the medullary region of the beet were surface disinfested with a $10 \%$ dilution of commercial Clorox $(5.25 \%$ sodium hypochlorite) for 2 to $3 \mathrm{~min}$, followed by a 2- to 3 min rinse in sterile water (17). An effort was made to use only tissue above and away from the rotted distal end of roots, to avoid possible secondary contamination. Root pieces were plated onto half-strength potato dextrose agar (PDA) amended with $300 \mathrm{ppm}$ streptomycin sulfate. Within 3 to 5 days, the fungus grew out from necrotic vascular bundles. Each isolate was recovered from a distinct beet root.

After initial isolation, each recovered isolate was single spored (27) on halfstrength PDA. Single-spored colonies were then increased in a liquid mineral salts medium (10) and stored on either sterile filter paper or soil. The most effective method was a modification of that of Correll et al. (7). It consisted of incubating agar plugs removed from the leading edge of singlespored colonies in the liquid medium. After $48 \mathrm{~h}$ on a rotary shaker at $100 \mathrm{rpm}$ (Model 3520, orbit shaker, Lab-line Instruments Inc., Melrose Park, IL), $1 \mathrm{ml}$ of the spore suspension was diluted with 15 $\mathrm{ml}$ of water and overlaid onto a piece of sterile filter paper placed on a half-strength PDA plate. Excess solution was poured off and the plate was incubated for 24 to $36 \mathrm{~h}$

Table 1. Vegetative compatibility groups (VCGs) among pathogenic isolates of Fusarium oxysporum f. sp. betae recovered from sugar beet and pigweed

\begin{tabular}{lcccccr}
\hline & \multicolumn{2}{c}{ Sugar beet } & & \multicolumn{2}{c}{ Pigweed } & \\
\cline { 2 - 3 } \cline { 5 - 6 } VCG & TR $^{\mathbf{a}}$ & NTR $^{\mathbf{a}}$ & & TR & NTR & Total \\
\hline VCG 1 & 43 & 16 & & 1 & 3 & 63 \\
VCG 2 & 3 & 3 & & 0 & 0 & 6 \\
VCG 3 & 12 & 2 & 0 & 2 & 16 \\
VCG 4 & 1 & 1 & 0 & 0 & 2 \\
VCG 5 & 1 & 1 & 0 & 0 & 2 \\
VCG 6 & 1 & 0 & 0 & 1 & 2 \\
VCG 7 & 3 & 1 & 0 & 0 & 4 \\
SMM & 2 & 0 & 0 & 0 & 2 \\
SI $^{\text {c }}$ & 9 & 1 & 0 & 1 & 11 \\
UK $^{\text {d }}$ & 19 & 3 & 0 & 2 & 24 \\
\hline
\end{tabular}

a $\mathrm{TR}=$ tip rot isolate; NTR = non tip rot isolate.

b Single member Nit M.

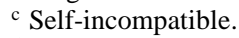

d Unknown. at room temperature. After this time, the filter paper (containing a carpetlike layer of hyphae) was removed from the plate, air dried individually in empty petri plates, cut into pieces, and stored at $4{ }^{\circ} \mathrm{C}$ in $1.5-\mathrm{ml}$ centrifuge tubes.

Pathogenicity testing. Susceptible sugar beet seeds, cv. Tx 9 or Ranger, were planted into Ray Leach Cone-Tainers (Steuwe and Sons, Corvallis, OR) with a soil mix of commercial topsoil and sand (1:1 ratio). After 4 to 6 weeks, the entire root mass and soil mix combination was removed, dipped into inoculum, and placed back into the Cone-Tainers. Inoculum consisted of the single-spored isolates grown in the liquid mineral salts medium for 36 to $48 \mathrm{~h}$. Microspore concentration at the time of inoculation was approximately $1 \times 10^{6}$ spores per milliliter. Five plants (replications) were inoculated with each isolate. Plants were watered daily. After another 4 to 6 weeks of incubation in the greenhouse, plants were washed free of the soil mix and observed for root lesions.

Roots from all five replications were rated for disease on a 0 to 2 scale. Roots given a 0 rating appeared healthy with no visible lesions. A rating of 1 was used for plants with lesions and necrosis confined to feeder roots, while a 2 was used for plants with tap root lesions or tip rot symptoms. Only those isolates causing plants to receive a rating of 1 or 2 on at least four of the five replications were considered to be pathogenic to sugar beet and, therefore, were termed FOB. Nonpathogenic strains were discarded and not used for vegetative compatibility evaluations. Pathogenicity tests were repeated once.

Vegetative compatibility testing. After pathogenicity testing, 28 isolates were determined to be nonpathogenic. The remaining 132 pathogenic isolates were tested for vegetative compatibility. Mutants were generated for each strain as described previously $(5,6,30)$ on minimal medium, or potato dextrose agar, with $1.5 \%$ potassium chlorate. Many isolates failed to form mutants on these media, so chlorate concentrations were often increased to $3 \%$, and in some cases to $4.5 \%$. Mutant sectors appearing on the chlorate media were transferred to minimal medium containing nitrate as the sole nitrogen source. Those sectors that grew as thin, expansive colonies with no aerial mycelium were considered to be nit mutants $(5,6)$.

Twenty-eight isolates representative of the different counties, hosts, and symptom types were initially selected for vegetative compatibility tests. Nit mutants were produced and phenotyped according to the methods of Correll et al. with media containing different nitrogen sources (6). They were paired in all possible combinations on minimal medium to determine the number of VCGs. For any isolates not forming heterokaryons, more mutants were generated, phenotyped, and tested against each other in a further attempt to establish VCG identity $(12,13)$.

After VCGs were established for the initial 28 isolates, the remaining 104 isolates were treated in the same manner. At least one nit 1 or nit 3 was produced for each isolate and paired with a Nit $\mathrm{M}$ from one member of each of the established VCGs. As with the initial testers, many recalcitrant isolates were subjected to higher chlorate concentrations to obtain mutants. All pairings were repeated at least once. Those isolates that did not match with any of the VCGs after two attempts were then tested for self-incompatibility by pairing at least two Nit Ms with one nit 1 or nit 3 produced from that isolate.

An additional 35 isolates were also evaluated for vegetative compatibility. This collection included 32 isolates from five other sugar-beet-growing states, two Texas isolates originally collected in 1987 and designated as TX 4 and TX 5 in a previous study (26), and one ATCC isolate originating from Oregon.

At least one representative $\mathrm{Nit} \mathrm{M}$ was found for isolates from each of the other sugar-beet-growing states. Those Nit Ms were tested in all possible combinations against a nit 1 or nit 3 mutant generated for each isolate collected from California, Oregon, Wyoming, Montana, and Colorado. They were also paired with the established Texas VCGs. After two tests, no further mutant generations or vegetative compatibility testings were attempted with these isolates.

\section{RESULTS}

Seven distinct VCGs were established that contained two or more members (Table 1). All 132 isolates were able to produce nit mutants. Ninety-five of the 132 isolates of FOB from Texas fell into one of the seven VCGs. Of the 95 isolates that were assigned to a specific VCG, 63 (66\%) were placed into VCG 1 (Table 1). VCG 3 contained 16 isolates, while VCGs 2, 4, 5, 6 , and 7 contained $6,2,2,2$, and 4 isolates, respectively.

Two other isolates were found that produced Nit Ms and were self-compatible, but did not pair with any other isolates. Eleven isolates were determined to be selfincompatible. The remaining 24 isolates could not be placed into any of the seven VCGs. Therefore, these isolates were classified as unknown (Table 1).

After both intra- and interstate pairings of the additional 35 isolates were performed in all possible combinations, none were found to be compatible with any other strain collected from a different state. Both Texas isolates used in the previous study (26) belonged to the largest of the established Texas VCGs (VCG 1). The one ATCC isolate was unable to form a heterokaryon with any other isolate, even those from Oregon.

Sugar beet isolates from other states, like those collected from Texas, exhibited a 
considerable amount of variation. Eight of the 12 Oregon strains were placed into two major VCGs, with two self-incompatible members and two unknowns. Four singlemember Nit Ms were found among the nine Colorado strains, with the remaining five isolates unknown. At least one VCG was established for each of the other three states (Table 2).

\section{DISCUSSION}

One of the major objectives of this study was to determine if the different symptoms on sugar beets could be correlated with distinctive VCGs. Our results indicate that there is no relationship between these variables. Both symptom types were included in six of the seven VCGs. However, the root rot symptom is still the predominate symptom observed in Texas, unlike in other sugar-beet-growing states. Isolates causing this symptom type constituted $72 \%$ of the total number evaluated (95 of 132).

The symptoms on pigweed were generally less severe than on sugar beet. Most infected pigweed plants in the field exhibited a mild wilting, while sugar beets showed severe wilting, interveinal yellowing, and leaf scorching. Root symptoms on pigweed were likewise different from those on sugar beets. They were characterized by slight discoloration of limited numbers of vascular bundles and no external symptoms, rather than necrosis of multiple vascular elements and severe cortical rot of the taproot, as was the case with sugar beet. One isolate from pigweed did cause obvious necrotic lesions on the tap root and was classified as a tip rot isolate, but this was an exception.

Our study also revealed considerable genetic diversity among Texas isolates, as illustrated by the multiple VCGs discovered. Since vegetative compatibility requires a relatively high degree of genetic relatedness between individuals, the presence of a number of VCGs implies that much variation exists between individuals in a population $(5,18,22)$. Although several VCGs were revealed, it is significant that over half of the isolates were placed into one major VCG. In addition, two singlemember Nit Ms were also identified. Previous VCG studies $(8,9,12)$ have similarly recovered a number of single-member $\mathrm{Nit}$ Ms. We chose not to establish a new VCG without at least two members. In addition to multiple VCGs, the large number of self-incompatible and/or unknown isolates further suggests a substantial amount of variation among FOB isolates in Texas. Jacobson and Gordon (18) also found selfincompatible isolates occurring with Fusarium oxysporum Schlechtend.:Fr. f. sp. melonis W. C. Snyder \& H. N. Hans. (FOM), the wilt pathogen of muskmelon.

Genetic diversity also was clearly evidenced by the large number of possible VCGs found among those isolates collected from growing areas outside of
Texas. Technically, nine new VCGs could have been added to the ones found in Texas, two from Oregon, four from Colorado, and one each from Montana, Wyoming, and California. However, because most of these isolates were gifts from other investigators and, to our knowledge, not tested for pathogenicity, additional new VCGs will not be designated until more extensive research on these isolates has been conducted. Nevertheless, these data are representative of the variation present among FOB isolates from sugar beets in the U.S.

These results also support and confirm previous attempts to study genetic relationships between isolates of FOB. With the use of three enzymes and isozyme profile analysis, Martyn et al. (26) compared two Texas isolates with several others from California and Oregon. They found the Texas isolates to be genetically distinct from the others. Fisher and Gerik (11) obtained similar results with random amplified polymorphic DNA (RAPD) polymerase chain reaction (PCR). They found that isolates from California, Montana, and Oregon all had unique banding patterns, while those from Texas and Wyoming exhibited similar ones. Our study showed no vegetative compatibility between Texas and Wyoming isolates. However, this could be due to the small number of isolates (four) from Wyoming that were evaluated. Many more isolates need to be tested to clarify the relationship between FOB isolates from Texas and Wyoming.

Vegetative compatibility is useful for demonstrating genetic similarities among isolates. An example of VCGs demonstrating a lack of genetic diversity was reported for the Bayoud disease of date palm caused by $F$. oxysporum Schlechtend.:Fr. f. sp. albedinis (Killian and Maire) Gordon. A collection of 44 isolates all belonged to a single VCG, and no polymorphisms were observed in restriction fragment length polymorphism (RFLP) studies from mtDNA or RAPD analysis (33). VCGs have also been shown to align closely to clonal lineages in isolates of the banana wilt pathogen Fusarium oxysporum Schlechtend.:Fr. f. sp. cubense (E. F. Sm.) W. C. Snyder \& H. N. Hans. These lineages were determined from multi-locus haplotypes from single-copy RFLPs (H. C. Kistler, unpublished). From this same pathogen, VCGs were demonstrated to be statistically as accurate at implying clonal lineages as were electrophoretic karyotypes, as measured by chromosome number and genome size (3). VCGs have also aligned with distinctive mtDNA and IGS haplotypes in Fusarium oxysporum f. sp. melonis $(1,2)$. Therefore, VCGs can be good predictors for underlying genetic similarities within many formae speciales, but not necessarily for genetic differences (H. C. Kistler, unpublished).

Another interesting aspect of this study concerned isolates collected from the Bush Farm in Potter County. This is a research farm north of the experiment station in Bushland, Texas. Until 1992, no sugar beets had ever been grown at this location. Beginning in 1992, 23 FOB isolates were collected and isolated from diseased beets in three separate fields over a 3-year period. Each field where collections were made represented first-time sugar beet cultivation on that particular piece of ground. Nineteen of those 23 individuals were compatible with four of the seven established Texas VCGs. Fifteen of the 19 were placed into the largest group, VCG 1 . The Bush Farm, and the FOB populations found there, seem to represent a microcosm of the entire Texas growing region. Even among this small collection of isolates, over half of the known VCGs in Texas were represented and most $(65 \%)$ belonged to the major VCG. Interestingly, this is approximately the same percentage of all Texas isolates that were assigned to VCG 1 (65 of 95 [66\%]).

The lack of genetic homology detected between the FOB isolates from different states $(11,16,26,31)$ suggests that these isolates represent distinct, isolated populations indigenous to their respective areas. Because the Bush Farm isolates (collected from virgin sugar beet ground each time) were compatible with isolates from fields known to be infested with FOB for 10 to 15 years, we surmise that these fungal populations are endemic to Texas soils. Gordon and Okamoto (12) concluded that pathogenic isolates of FOM were clonal populations derived from introduction of a single genotype, whereas nonpathogenic isolates were apparently native to California soils. Initially, we thought that isolates in Texas could have been introduced, possibly on sugar beet seed from Oregon $(14,25)$. However, the fact that no compatibility was ever detected between Texas

Table 2. Fusarium oxysporum isolates from sugar beet tested for vegetative compatibility, from states other than Texas

\begin{tabular}{lcccc}
\hline Source & Isolates tested (no.) & VCGs $^{\text {a }}($ no.) & Nit Ms recovered & Unknown \\
\hline Colorado & 9 & 0 & 4 & 5 \\
Wyoming & 4 & 1 & 1 & 2 \\
Montana & 5 & 1 & 1 & 3 \\
Oregon $^{\text {b }}$ & 13 & 2 & 4 & 3 \\
California $^{2}$ & 2 & 1 & 1 & 0 \\
\hline
\end{tabular}

a Vegetative compatibility groups.

${ }^{b}$ Also includes one ATCC isolate that was not compatible with any other isolate. 
and Oregon isolates seems to rule out this possibility and supports our premise (based upon VCG results) that these FOB isolates appear to be endemic to Texas.

It is possible that FOB populations could have been present in Texas soils for some time, surviving in low numbers on pigweed or some other plant species. MacDonald and Leach (24) found several weeds, including lamb's-quarters (Chenopodium album L.), black mustard (Brassica nigra (L.) W. Koch), and wild dill (Anethum graveolens $\mathrm{L}$.) to be symptomless carriers of FOB. The disease may have gone undetected until several cycles of sugar beet culture increased populations to levels that caused notable root rot symptoms and yield loss. Sugar beet production in Texas has occurred since the late 1960s, but FOB was not noticed until 1981 when severe yield losses began occurring (26). With 3- to 4year rotation schedules typical for the Texas Panhandle, it likely took this long for soil populations of FOB to build up to damaging levels.

A study in South Africa found that isolates of Fusarium oxysporum f. sp. tuberosi W. C. Snyder \& H. N. Hans. that caused different disease symptoms (stem-end rot, dry rot, and wilt) could often be placed into distinct VCGs consistent with symptom type (34). This hypothesis did not hold true for FOB isolates in Texas and the two major symptom types. Although there is variation among Texas isolates, most are still found to belong to one of several VCGs. These individuals are clearly different from isolates from other areas of the U.S., symptomatically, morphologically, and genetically $(11,16,17,26,31)$. It has been suggested that Texas isolates of FOB be placed in a new formae speciales to reflect these differences (26). This has been done before to distinguish between the tomato wilt pathogen, Fusarium oxysporum Schlechtend.:Fr. f. sp. lycopersici (Sacc.) W. C. Snyder \& H. N. Hans., and the tomato root and crown rot pathogen, Fusarium oxysporum Schlechtend.:Fr. f. sp. radicis-lycopersici W. R. Jarvis \& Shoemaker, due to differences in symptoms and temperature optima (19). Additional studies need to be conducted to better characterize selected FOB isolates under environmentally controlled conditions. Isolates should also be evaluated by molecular techniques, and compared with the established VCGs, to more thoroughly substantiate possible phylogenetic relationships.

\section{ACKNOWLEDGMENTS}

We would like to thank G. Fisher and J. Gerik for providing isolates from California, Montana, and Wyoming that were used in this study.
LITERATURE CITED

1. Appel, D. J., and Gordon, T. R. 1994. Local and regional variation in populations of Fusarium oxysporum from agricultural field soils. Phytopathology 84:786-791.

2. Appel, D. J., and Gordon, T. R. 1995. Intraspecific variation in populations of Fusarium oxysporum based on RFLP analysis of the intergenic spacer region. Exp. Mycol. 19:120128 .

3. Boehm, E. W. A., Ploetz, R. C., and Kistler, H. C. 1994. Statistical analysis of electrophoretic karyotype variation among vegetative compatibility groups of Fusarium oxysporum f. sp. cubense. Mol. Plant-Microbe Interact. 7: 196-207.

4. Bosland, P. W., and Williams, P. H. 1987. An evaluation of Fusarium oxysporum from crucifers based on pathogenicity, isozyme polymorphism, vegetative compatibility, and geographic origin. Can. J. Bot. 65:2067-2073.

5. Correll, J. C. 1991. The relationship between formae speciales, races, and vegetative compatibility groups in Fusarium oxysporum. Phytopathology 81:1061-1064.

6. Correll, J. C., Klittich, C. J. R., and Leslie, J. F. 1987. Nitrate nonutilizing mutants of Fusarium oxysporum and their use in vegetative compatibility tests. Phytopathology 77: $1640-1646$

7. Correll, J. C., Puhalla, J. E., and Schneider, R. W. 1986. Identification of Fusarium oxysporum f. sp. apii on the basis of colony size, virulence, and vegetative compatibility. Phytopathology 76:396-400.

8. Elias, K. S., and Schneider, R. W. 1991. Vegetative compatibility groups in Fusarium oxysporum f. sp. lycopersici. Phytopathology 81:159-162.

9. Elmer, W. H., and Stephens, C. T. 1989. Classification of Fusarium oxysporum f. sp. asparagi into vegetatively compatible groups. Phytopathology 79:88-93.

10. Esposito, R., and Fletcher, A. M. 1961. The relationship of pteridine biosynthesis to the action of copper 8-hydroxyl-quinolate on fungal spores. Arch. Biochem. Biophys. 93: 369-376

11. Fisher, G. A., and Gerik, J. S. 1994. Genetic diversity of Fusarium oxysporum isolates pathogenic to sugar beets. (Abstr.) Phytopathology 84:1098.

12. Gordon, T. R., and Okamoto, D. 1991. Vegetative compatibility groupings in a local population of Fusarium oxysporum. Can. J. Bot. 69:168-172.

13. Gordon, T. R., and Okamoto, D. 1992. Population structure and the relationship between pathogenic and nonpathogenic strains of $\mathrm{Fu}$ sarium oxysporum. Phytopathology 82:73-77.

14. Gross, D. C., and Leach, L. D. 1973. Stalk blight of sugarbeet seed crops caused by $\mathrm{Fu}$ sarium oxysporum f. sp. betae. (Abstr.) Phytopathology 63:1216.

15. Harveson, R. M., and Rush, C. M. 1994. Evaluation of fumigation and rhizomaniatolerant cultivars for control of a root disease complex of sugar beets. Plant Dis. 78:11971202.

16. Harveson, R. M., and Rush, C. M. 1995. Evaluation of genetic variability among Fusarium oxysporum $\mathrm{f}$. $\mathrm{sp}$. betae isolates by vegetative compatibility. (Abstr.) Phytopathology 85:1117.

17. Harveson, R. M., and Rush, C. M. 1995. Studies of vegetative compatibility among isolates of Fusarium oxysporum f. sp. betae causing different disease symptoms. (Abstr.) J. Sugar Beet Res. 32:142.

18. Jacobson, D. J and Gordon, T. R. 1988 Vegetative compatibility and self-incompatibility within Fusarium oxysporum f. sp. melonis. Phytopathology 78:668-672.

19. Jarvis, W. R., and Shoemaker, R. A. 1978. Taxonomic status of Fusarium oxysporum causing foot and root rot of tomato. Phytopathology 68:1679-1680.

20. Katan, T., and Katan, J. 1988. Vegetativecompatibility grouping of Fusarium oxysporum f. sp. vasinfectum from tissue and the rhizosphere of cotton plants. Phytopathology 78:852-855.

21. Larkin, R. P., Hopkins, D. L., and Martin F. N. 1990. Vegetative compatibility within Fusarium oxysporum f. sp. niveum and its relationship to virulence, aggres siveness, and race. Can. J. Microbiol. 36:352-358.

22. Leslie, J. F. 1990. Genetic exchange within sexual and asexual populations of the genus Fusarium. Pages 37-48 in: Fusarium Wilt of Banana. R. C. Ploetz, ed. American Phytopathological Society, St. Paul, MN.

23. Leslie, J. F. 1993. Fungal vegetative compatibility. Ann. Rev. Phytopathol. 31:127-150.

24. MacDonald, J. D., and Leach, L. D. 1976 Evidence for an expanded host range of $\mathrm{Fusa}$ rium oxysporum $\mathrm{f}$. $\mathrm{sp}$. betae. Phytopathology 66:822-827.

25. MacDonald, J. D., and Leach, L. D. 1976. The association of Fusarium oxysporum $\mathrm{f}$. sp. betae with nonprocessed and processed sugarbeet seed. Phytopathology 66:868872.

26. Martyn, R. D., Rush, C. M., Biles, C. L., and Baker, E. H. 1989. Etiology of a root rot disease of sugar beet in Texas. Plant Dis. 73:879 884.

27. Nelson, P. E., Tousson, T. A., and Marasas, W. F. O. 1983. Fusarium Species: Illustrated Manual for Identification. Pennsylvania State University Press, University Park.

28. Ploetz, R. C. 1990. Variability in Fusarium oxysporum f. sp. cubense. Can. J. Bot. 68: 1357-1363

29. Ploetz, R. C., and Correll, J. C. 1988. Vegetative compatibility among races of Fusarium oxysporum f. sp. cubense. Plant Dis. 72:325328.

30. Puhalla, J. E. 1985. Classification of strains of Fusarium oxysporum on the basis of vegetative compatibility. Can. J. Bot. 63:179-183.

31. Rush, C. M., and Martyn, R. D. 1991. Variation in sugar beet susceptibility to isolates of Fusarium oxysporum f. sp. betae from Texas and Oregon. (Abstr.) Phytopathology 81: 1200

32. Stewart, D. 1931. Sugar-beet yellows caused by Fusarium conglutinans var. betae. Phytopathology 21:59-70.

33. Tantaoui, A., Ouinten, M., Geiger, J.-P., and Fernandez, D. 1996. Characterization of a single clonal lineage of Fusarium oxysporum f. sp. albedinis causing bayoud disease of date palm in Morocco. Phytopathology 86:787792.

34. Venter, S. L., Theron, D. J., Steyn, P. J., Ferreira, D. I., and Eicker, A. 1992. Relationship between vegetative compatibility and pathogenicity of isolates of Fusarium oxysporum $\mathrm{f}$. sp. tuberosi from potato. Phytopathology 82 . 858-862. 